\title{
Tip 2 diyabetli hastaların aile hekimiyle iletişimi ile ilgili görüş ve deneyimleri: Kalitatif çalıșma
}

\author{
The opinions and experiences of Type 2 diabetic patients with family physicians \\ about communication: Qualitative study
}

\section{Duygu Ayhan Başer*, Rabia Kahveci, Hilal Aksoy, Pınar Döner, İsmail Kasım, İrfan Şencan, Adem Özkara}

Aile Hekimliği Kliniği (Dr. D. A. Başer, Doç. Dr. R. Kahveci, Dr. İ. Kasım, Dr. İ. Şencan), Ankara Numune Eğitim ve Araştırma Hastanesi, TR-06100 Ankara, Toplum Sağlı̆̆1 (Dr. H. Aksoy), Etimesgut Toplum Sağlığı Merkezi, TR-06793 Ankara, Aile Hekimliği Anabilim Dalı (Yrd. Doç. Dr. P. Döner), Mustafa Kemal Üniversitesi Tıp Fakültesi, TR-31000 Hatay, Aile Hekimliği Anabilim Dalı (Prof. Dr. A. Özkara), Hitit Üniversitesi Tıp Fakültesi, TR-19000 Çorum

\begin{abstract}
Özet
Amaç. Bu niteliksel çalışmada, Tip 2 diyabetli hastaların takiplerinde birinci basamağı tercih etme durumlarının, birinci basamaktaki DM yönetimine dair görüşlerinin, aile hekimleri ile aralarındaki iletişiminin ve aile hekimleri ile iletişimlerinde etkili olan faktörlerin ve nedenlerinin saptanması amaçlandı. Yöntem. Çalışmamıza araştırmaya katılmaya gönüllü olanlardan, maksimum çeşitlilik örneklemesi ile seçilmiş 20 Tip 2 diyabetli hasta katıldı. Hastalar ile derinlemesine, yarı yapılandırılmış, yüz yüze görüşmeler yapıldı. Görüşmelerin tümü dijital olarak kaydedildi ve yazıya aktarıldıktan sonra kalitatif olarak analiz edildi. Bulgular. DM hastaları, kapsaml, bütüncül yaklaşımı ve aile sağlığı merkezine kolay ulaşımından dolayı takiplerinde aile hekimini seçebilmektedirler. Aile hekiminde aradıkları özellikler ise samimiyet, ulaşım kolaylığı, empati ve yüksek bilgi düzeyidir. Sonuç. Çalışmamızda, sağlık hizmetleri içinde çok önemli bir yere sahip olan birinci basamak sağlık sistemlerinde çekirdek yeterliliklerinin, DM gibi kronik hastalıkların yönetiminde hastaların aile hekimlerinden beklentileri doğrultusundaki gereken özellikleri karşıladığı saptandı.
\end{abstract}

Anahtar sözcükler: Aile hekimliği, birinci basamak sağlık sistemleri, diyabet yönetimi, hasta hekim iletişimi, kalitatif araştırma

\begin{abstract}
Aim. This qualitative study is aimed to determine the status of Type 2 diabetic patients to prefer primary care during follow-up, their views on DM management at primary care, the communication between them and family physician and the influential factors and causes of these factors in communication with family physicians. Methods. 20 Type 2 diabetic patients were selected with maximum variation sampling through the patients volunteered to participate in this research. We conducted in-depth, semi-structured, face to face interviews. Interviews were audiorecorded and transcribed, and qualitatively analyzed afterwards. Results. DM patients may select family physicians during their follow-up due to comprehensive, holistic approach and easy access to physicians and family health center. The expected features of family physicians are friendliness, ease of access, empathy and the high level of knowledge. Conclusion. In our study, we detected that the features of family physicians, in case of following up chronic diseaases such as DM, that are expected by the patients are fully met by the core competencies of family medicine at primary health care, which has a very important place in the system of health services.
\end{abstract}

Keywords: Diabetes management, family medicine, patient-physician communication, primary health care systems, qualitative research 
Geliş tarihi/Received: 21 Kasım 2014; Kabul tarihi/Accepted: 13 Aralık 2014

\author{
*İletişim adresi: \\ Dr. Duygu Ayhan Başer, Aile Hekimliği Kliniği, Ankara Numune Eğitim ve Araştırma Hastanesi, \\ TR-06100 Ankara. E-posta: duygu_ayhan86@hotmail.com
}

*Araştırmamızın etik kurul onayı Ankara Numune Eğitim ve Araştırma Hastanesi Etik Kurulu’ndan alındı ve araştırma Helsinki Deklarasyonu prensiplerine uygun olarak yapıldı.

\title{
Giriş
}

Dünya genelinde aile hekimleri, bütün yaş gruplarındaki kişilere, etnik yapı, cinsiyet, din, dil, eğitim düzeyi ve kişisel alışkanlıklarını gözetmeksizin sağlık hizmeti sunmaktalar [1]. Aile hekimleri, polikliniğe başvuran hastaların hem akut problemlerinin çözümünde hem de kronik hastalıklarının yönetiminde önemli bir yer teşkil etmekteler.

Yapılan çalışmalarda birinci basamağa yapılan tüm poliklinik başvurularının \%72'sinin kronik bir hastalık nedeniyle olduğugösterilmiştir [2,3]. Ülkemizde, 5 ay boyunca aile hekimliği polikliniğine ilk kez başvuran hastaların \%67,4'ünün kronik bir sağlık sorunu olduğu saptanmıştır [3, 4]. Kronik hastalıklar arasında prevalansı her geçen gün daha da artmakta olan, iyi yönlendirme, erken teşhis ve tedavi ile çok iyi bir şekilde yönetilebilecek olan diabetes mellitus (DM) özellikle dikkat çekmektedir. TURDEP II çalışması Türk erişkin toplumunda diyabet yaygınlığının \%13,7'ye ulaştığını belirterek, DM yönetiminin gereği ve önemini bir kez daha gözler önüne sermiştir [5].

Aile hekimlerinin, DM yönetimindeki yeri yadsınamaz. Aile hekimlerinin, DM dahil tüm kronik hastalıkların yönetiminde gerek bilgileri ile hastalığı yöneterek gerekse de hastaları ile iyi bir iletişim sağlayarak görevlerini en iyi şekilde yerine getirmeleri gerekmektedir. DM gibi kronik hastalıklarda eğer hasta hekim arasında görüş birliği sağlanamaz ise; iletişim kesintiye uğrar ve tedavi yetersiz kalır. Hasta hekim arası karşı1ıklı anlayış eksikliği, hasta uyumunun azalmasına neden olacak ve bu hastalıkların tedavisinde hastanın tedaviye daha az katılımına neden olacaktır. İyi bir hasta-hekim iletişimi; rahatlama, problem çözme, stresi giderme, bilgi verme, ilişkileri biçimlendirme ve sürdürme, duyguları açıklama, ikna etme, karar verme gibi birçok amaca hizmet eder [6]. Yapılan çalışmalar hekimin iletişim düzeyinin hastaların tedaviye uyumu, hoşnutluk düzeyi ve sağlık sonuçları üzerine etkilerinin yanı sıra, hekimin mesleğinden ve profesyonel kimliğinden memnuniyetini de etkilediğini göstermiştir [7].

Kalitatif çalışmalar neden insanların belli şekilde davrandıklarını, düşünce ve davranış eğilimlerini, insanların çevrelerindeki olaylardan nasıl etkilendiklerini daha iyi anlamamızı sağlar. Kalitatif araştırmalarda, veriler bireylerle birebir görüşmeler, grup görüşmeleri veya gözlem sonucunda elde edilmektedir. Veri toplama zaman alıcı ve veriler fazla olduğu için küçük örneklemler kullanılmaktadır. Bu çalışmalarda güvenirlik ve geçerliliği değerlendirmek için kullanılan kriterler de kantitatif çalışmalardan farklılık göstermektedir [8].

$\mathrm{Bu}$ çalışmanın amacı, sağlık alanında yeni kullanılmaya başlanan kalitatif çalışma yöntemini kullanarak Tip 2 diyabetli hastaların takiplerinde birinci basamağı tercih etme durumlarını, birinci basamaktaki DM yönetimine dair görüşlerini, aile hekimleri ile aralarındaki iletişimi ve aile hekimleri ile iletişimlerinde etkili olan faktörleri ve nedenlerini saptamaktır.

\section{Gereç ve yöntem}

Ankara Numune Eğitim ve Araştırma Hastanesi Aile Hekimliği polikliniklerine 15.07.2013-15.08.2013 tarihleri arasında gelen, 20 Tip 2 diyabetli hasta çalışma kapsamına alındı. Hastalar araştırmaya katılmaya gönüllü olanlardan, maksimum çeşitlilik örneklemesi ile seçildi. Kendisi veya yakınları için, son bir yıl içinde, bir birinci 
basamak hekimine Tip 2 diyabet yönetimi ile ilgili en az bir kez danışmış olan hastalar araştırmaya dahil edildi.

Veri toplamak amacıyla, derinlemesine bireysel görüşmeler yapıldı. Görüşme formunun hazırlanmasında literatür bilgilerinin yanında, daha önce kalitatif çalışmalar yapmış dört öğretim üyesinin bilgi ve görüşlerinden de yararlanıldı. Hastalara derinlemesine, yarı yapılandırılmış sorular yüz yüze görüşmeler ile soruldu. Kullanılan görüşme formları aynı zamanda demografik soruları da içermekteydi. Görüşmelerin tümü onay alındıktan sonra ses kayıt cihazıyla kaydedildi. Özel bir odada yapılan görüşmeler yaklaşık 8-14 dakika sürdü.

Kayıtlar tüm vurgular ve özel ifadeler içerecek şekilde aynen yazıya aktarıldı. Ses kayıtları çözümlenirken, her hastaya bir kod numarası verilerek kayıt edildi. Kayıt altına alınan görüşmeler çözümlendikten sonra içerik analizi iki ayrı araştırmacı tarafından karşılaştırılarak uzlaşma sağlandı. Her bir hastanın en çok üzerinde durduğu konular yazılı metin üzerinde işaretlendi ve "anahtar kelimeler listesi" (opencodings list) oluşturuldu. Kodlamayı takiben kategoriler oluşturuldu. Anahtar kelime listesinde yer alan kelimelerden birbiri ile bağlantılı olanlar "minor kategoriler" olarak adlandırılan küçük alt başlıklar altında toplandı. Tüm bu minör kategoriler her röportajda listeye eklendi ve liste güncellendi. Minor kategoriler ise daha kapsamlı ortak başlıklar olan "major kategoriler" adı altında toplandı. Son olarak major kategorilerin ortak yönleri ile gruplandırılması şeklinde "ana temalar" belirlendi. Çalışmanın sonuçlarının değerlendirilmesinin temel unsurunu ana temalar oluşturdu.

\section{Bulgular}

On bir erkek, 9 kadın hasta ile röportaj yapıldı. Hastaların yaş, cinsiyet, eğitim seviyesi, medeni durumu, hastalığa sahip olduğu süre, insülin kullanma durumu, HbA1c seviyeleri ve görüşme süresinin yorumlanmasında yüzde ve sayı hesabı kullanıldı. Çalışmaya katılan hastaların özellikleri Tablo 1'de verilmiştir.

Kalitatif değerlendirme sonucu belirlenen ana temalar şunlardı: DM yönetiminde aile hekimlerinin rolü ve yeri, aile hekimi-hasta arası iletişim, aile hekimi seçimi. Söz konusu temalar araştırmacıları onlara yönlendiren analiz detayları ve alıntılar ile birlikte aşağıda detaylandırılmaktadır. Bulgular sunulurken yanıtlardan sonra parantez içinde kişilerin röportaj numarası belirtildi.

Tablo 1. Araştırmaya dahil edilen hastaların demografik ve karakteristik özellikleri (n=20).

\begin{tabular}{llll}
\hline Hasta özellikleri & & Sayı (n) & Yüzde (\%) \\
\hline Yaş & $21-40$ & 3 & 15 \\
& $41-60$ & 7 & 35 \\
Cinsiyet & $61-80$ & 10 & 50 \\
Eğitim seviyesi & Erkek & 11 & 55 \\
& Kadın & 9 & 45 \\
& Okuma yazma yok & 2 & 10 \\
Medeni durumu & İlköğretim & 6 & 30 \\
& Lise & 9 & 45 \\
Hastalığa sahip olduğu süre & Lisans & 3 & 15 \\
& Evli & 20 & 100 \\
& Bekar & 0 & 0 \\
& $\leq 5$ yıl & 4 & 20 \\
& $6-10$ yıl & 5 & 25 \\
İnsülin kullanma durumu & $11-15$ yıl & 2 & 10 \\
& $16-20$ yıl & 4 & 20 \\
HbA1c seviyeleri & 20 yil< & 5 & 25 \\
& Evet & 4 & 20 \\
& Hayır & 16 & 80 \\
& $<6$ & 0 & 0 \\
Görüşme süresi & $6-7$ & 6 & 30 \\
& $7-9$ & 14 & 70 \\
& $9<$ & 0 & 0 \\
& $<5$ dak. & 1 & 5 \\
& $5-10$ dak. & 4 & 20 \\
& $10-15$ dak. & 15 & 75 \\
\hline \multirow{4}{*}{. } & & &
\end{tabular}




\section{DM yönetiminde aile hekimlerinin rolü ve yeri}

\section{Güven}

Hastaların büyük çoğunluğu, arada ikinci-üçüncü basamağa gitmekle birlikte, DM kontrolleri için aile hekimine başvurduklarını söylediler. Diğer hekimlere de gittiğini belirten hastalardan bazıları aynı tedavinin aile hekimi tarafindan da yapılabildiğini belirttiler. DM hastalığı açısından aile hekimine takip olmayı tercih eden hastalar, hekiminin gerektiğinde ikinci-üçüncü basamak hekimine sevk edeceği konusunda güven duyduğunu belirttiler; “...önce dahiliye doktoruna başvurmuştum, tedaviye başladıktan sonra ise aile hekimime de gidip, diğer doktorumla olan konuşmalarımı ve önerilerini anlattım. Bunun üzerine aile hekimimin de gerekenleri yaptığını düşünüyorum.” (R3); “... aile hekimim çok iyi. O ısrar etti bana, ihmal etme, git dedi. Tanımı o koydurdu. Takiplerimde hep aile hekimime giderim ben...." (R8); “...Kontrol kanlarımı aile hekimliğnde aldırıyorum. Hem yakın hem de seviyorum doktor hanımı. Hem de aynı şeyi yapıyor... Bir durumdan şüphelendiğinde git şu bölüme diyor zaten.” (R16); Hastalar DM gibi kronik bir hastalığa sahip olunduğunda kendilerini, tüm hastalık geçmişini çok iyi bilen aynı hekim tarafindan izlenmenin verdiği güvenden bahsettiler; "kontrole aile hekimime gidiyorum. Evime yakın, çocukları komşuya bırakmak kolay oluyor. Bir de güveniyorum, alıştık kendisine...Her şeyimi, tüm hastalıklarımı biliyor. Hemen anlıyor, hemen halloluyor her şey." (R6); 6 hasta ise aile hekimine başka nedenlerden dolay1 gittikleri halde DM kontrolü için gitmediklerini belirtti; “...çok sık uğramam; 2-3 ayda bir ancak hastalandığım, grip olduğum zaman, şikayetlerim olduğu zaman giderim. Şeker hastalığı için gitmem." (R7); "Diyabetim için özel doktorum var benim hep ona giderim. Aile hekimine başka şikayetim olursa gidiyorum, çocukları sık götürüyoruz.” (R15).

Hastalardan bir tanesi DM takibinin aile hekimliğinde yapılmadığını, endokrin bölümünün DM ile ilgilendiğini düşündüğü için gitmediğini söyledi; “....aile hekimime güveniyorum aslında ama alışmışım yıllardır Numune'ye gelirim şeker takibine. Şekere endokrin baktığı için aile hekimine gitmiyorum." (R20).

\section{Kolay ulaşım}

DM hastaları bakımlarının aile hekimliklerinde daha kolay ve daha hızlı yapılabildiğini, aile hekimine, aile sağlı̆̆ merkezine diğer uzman hekimlerden ve hastanelerden daha kolay erişebildiklerini belirttiler; "ben hep aile doktoruma giderim. Bizim evin karşısı hemen, sıra beklemek de yok...Hem güler yüzlü hem de hemen halleder işlerimi..." (R11), "...zaten çok yaşlıyım, nasıl gideyim büyük hastaneye...Aile hekimim hemen yakın evime. Hiç sıra beklemiyorum...” (R9).

\section{Süreklilik}

Hastalar DM gibi kronik bir hastalık durumunda aynı hekime başvurmanın avantajlarından da söz ettiler. Hastalık geçmişini çok iyi bilen ve hastaya bütüncül yaklaşabilen bir hekime sahip olmanın avantajlarından bahsettiler; "şikayetlerimi anlatmaya başlayınca aile hekimim zaten benim bütün hastalıklarımı da bildiği için daha kolay tanı koyuyor ve ilaçlarımı ona göre düzenliyor..." (R6).

\section{Kapsamlı bakım}

DM hastaları kronik bir hastalık için sürekli takiplerine gittikleri merkezde diğer sıkıntılarını da bildirebilmek ve hem zamandan kazanmak hem de aynı anda bir kaç hastalığın birden çaresini bulabilmenin verdiği rahatlıktan bahsettiler; "...zaten sürekli hastanedeyiz. Dahiliyeye gidiyorsun şekerine bakıyor ama başka şikayetim olduğunda sürekli başka bölümlere yönlendiriliyorum. Aile hekimime söylediğim zaman bütün şikayetlerimle de ilgileniyor..." (R9). 


\section{Aile hekimi-hasta arası iletişim}

\section{Samimiyet}

Yapılan görüşmelerin çoğunda diyabet hastaları aile hekimleri ile sıcak, güven dolu bir ilişki içinde olduklarını bildirdiler. Hastalar hekimleri ile ilişkilerinin resmiyetten uzak ve samimi olmasını tercih etmekteydiler; “...̇letişimimiz çok iyi, beni anlıyor. Çok sık gitmiyorum ama sıcakkanlı hoş görülü. ” (R3); “...Çok sık giderim aile hekimime. Komşularla da gideriz oturur konuşuruz, aileden biri o da. " (R8); “...bizim aile doktoru bizim kızımız gibi. Her şeyi tek tek anlatır..." (R11); "Çok sever ve güvenirim aile hekimime. Çok iyidir bilgisi. Diğer hastalıklarım için de ona giderim. Uzun uzun dinler. Benim anlayacağım gibi anlatır. Elime diyet listesi verdi geçen gittiğimde. Çok ilgili, çok memnunum." (R16).

\section{Güven}

Hastalar, tüm sorunlarını danışabileceği ve kendi ile ilgili her şeyi çok iyi bilen bir hekiminin olmasını, aile hekimlerine karşı olan güvenlerinin oluşmasında çok büyük bir etken olarak açıklamaktadırlar. Sürekli aynı hekim tarafından bakım veriliyor olmasını, değişiklerin takibi ve kapsamlı bakım açısından bir avantaj olarak nitelendirdiler; “...güveniyorum, sonuçta artık o sizi tanıyor siz onu tanıyorsunuz... Siz şikayetlerinizi anlatmaya başlayınca aile hekimim zaten benim bütün hastalıklarımı da bildiği için daha kolay tanı koyuyor ve ilaçlarımı ona göre düzenliyor..." (R6).

\section{Empati}

Doktorun kendini anlamasının iletişimlerinde çok önemli bir yere sahip olduğunu belirten hastalar, doktorun kendini hasta yerine koymasının onları daha iyi hissettirdiğinden ve bu durumun ilişkilerini daha da kuvvetlendirdiğinden bahsettiler; “...hastalığım daha çok yeni ve kendimi çok kötü hissediyorum. Doktoruma gittiğimde beni anlaması, bir an olsun kendini benim yerime koyması benim için ne kadar önemli anlatamam..." (R3).

\section{Aile hekimi seçimi}

Tüm hastaların aile hekimi seçimi konusundaki ortak düşüncesi, sağlık merkezinin eve yakın olması gerekliliğiydi. Bunun dışında hastalar aile sağlığı merkezi ile ilgili olarak imkanlarının iyi olması gerektiğinden bahsettiler.

Aile hekimi ile ilgili olarak ise hekimin yaşı ve cinsiyetinden çok bilgisi, samimi, sıcak olması ve sıkıntıyı hemen anlaması ön plana çıkmaktaydı; “...Ev hanımıyım, çocukların okulu, ev iş güç derken yakınlık en önemlisi. Tabi bir de cana yakın, güvenilir olduktan sonra, ben de yani derdimi anlayıp de yardımcı olduktan sonra daha ne olsun. Daha da bir şey istemem sonunda." (R3); "Aile hekimi seçiminde dil, din benim için etkili olmazd. Kriter beni anlaması işlemlerin hızlı yapılması, yakın olması, sıcak olması..." (R6); "Doktorun hastaya iyi davranması, güler yüzlü olması, eve yakın olmas1... arkadaş gibi olacaksın aile doktoru ile. Her istediğim zaman danışabilmek için aile hekimimi arayabilmem lazım. " (R13); "Uzak olmamal, hemen ulaşılabilmeli, sağlık merkezinin imkanları iyi olmalı. Doktor açısından da bilgi düzeyi yüksek olmalı ve hastanın dilinden anlamalı diye düşünüyorum. " (R14).

Nasıl bir aile hekimi istedikleri sorusunda hastaların ortak yanıtı bilgi düzeyinin yüksek olması isteğiydi; “...doktor konusuna hastasına hakim olmalı, iyi bilmeli ne yapması gerektiğini. " (R7); "Bilgisi iyi olmalı. Gereksiz tetkiklerle çok uğraştırmamalı beni... (R17).

Hastalardan 4 tanesi aile hekiminin seçiminde cinsiyetin önemli olduğunu belirttiler. Bunun nedeni olarak eş kıskançlığı, mahremiyet istemi belirtildi; "Doktorun hastaya iyi davranması, eve yakın olması lazım. Bir de bayan olsa daha iyi olur, eşim çok doktora gidiyor o da daha rahat eder. " (R5); “...bayan olduğu için kendimi daha rahat hissediyorum, erkek olsa utanırım çekinirim..." (R6); "Bayan olursa daha memnun oluyorum, tesettürlüyüm ondan daha rahat oluyor. Kültür, dil, din fark etmez benim için. Beni anliyor ve tedavi ediyor olmas1 yeterli." (R16). 
Hastalardan bir tanesi aile hekiminin uzman olup olmadığına önem verdiğini belirtti; "eğer aile hekimimi seçme şansım olsaydı; mesafeyi dikkate alırdım, uzman olup olmadığına bakardım..." (R2).

\section{Tartışma}

Günümüzde, kronik hastalıkların kontrolünde hastalık yönetimi ile ilgili kavramlar sağlık alanında ön plana çıkmaktadır. DM, sağlık bakımındaki en kompleks ve en önemli kronik hastalıklardan birisidir. Düzenli tedavi gerektirmesinden dolayı diyabetli hastaların sağlık hizmetlerinden yararlanmaları büyük önem taşımaktadır.

Hastalarla ilk temas noktası olan, bütüncül, kapsamlı, hasta merkezli yaklaşımı ile sağlık hizmetlerinde çok önemli bir yer teşkil eden birinci basamak sağlık sistemlerinin, kronik hastalık bakımında da hastaların genel taramalarla tanı almaları, takibinin düzenlenmesi ve takipte sürekliliği sağlamak adına önemli bir yeri vardır.

WONCA (World Organization of National Colleges, Academies and Academic Associations of General Practitioners/Family Physicians) tarafindan da aile hekiminin çekirdek yeterlilikleri birinci basamak yönetimi, kişi merkezli bakım, özgün problem çözme becerileri, kapsamlı yaklaşım, toplum yönelimli olma ve bütüncül yaklaşım olarak belirtilmiştir [9].

Çalışmamızda DM hastaları, birinci basmakta güven ortamını sağlanması nedeni ile hastalıklarının takibinde birinci basamağı tercih ettiklerini belirttiler. Bu güvenin oluşumunda en etkili faktörler ise; sürekli aynı hekim tarafindan bakım veriliyor olmasının hastaların daha yakından izlendiği ve hastalıklarındaki değişimin daha iyi gözlendiği hissini edinmeleri, hekim ile birbirlerini tanıyor olman durumunun hastayı daha iyi hissettirmesidir. Güldal ve ark. [10] da kalitatif tipteki çalışmalarında aynı hekim tarafından bakım almanın hastaya verdiği güvenden bahsetmiş ve bu güvenin ailenin diğer fertlerinin de aile hekimine başvurmasını teşvik ettiğini belirtmişlerdir. Infante ve ark. [11] kronik hastalığı olan hastaların birinci basamak hekimlerinden beklentileri ile ilgili yaptıkları kalitatif çalışmalarında iyi bir aile hekiminin özelliklerini tanımlarken güven kavramının öneminden bahsetmiş ve tedavinin devamlılığında çok önemli bir yer teşkil ettiğini bildirmişlerdir. Bültzingslöwen ve ark. [12] birinci basamakta hasta hekim iletişimi ile ilgili yaptıkları çalışmada hasta açısından güven kavramını açmış ve etkileyen faktörleri tek tek ele almışlardır. Yapılan kalitatif analiz sonucu 4 ana faktör saptanan çalışmadaki bu faktörler; uyum, bakımda tutarlılık, ilişkiye inanç ve sürdürülebilirlik olarak belirlenmiştir.

Yapılan çalışmalardan da görüldüğü gibi tüm hastalarda olmakla birlikte devamlı olarak takibi gereken DM hastalarının birinci basamak sağlık sistemlerinde takip ve tedavi olmayı seçme nedenlerinin ve yine bir aile hekiminde olmasını istedikleri özelliklerin başında güven gelmektedir. Güven kavramı hem kişisel iletişim hem de hastalık düzeyinde ele alınmalı ve bu noktada dikkat edilmelidir.

Hem DM yönetiminde aile hekimini tercih nedeni olarak hem de bir aile hekimi ve aile sağlığı merkezinden beklentiler arasında kolay ulaşım isteği gelmektedir. Kronik hastalığ olan hastalar sürekli olarak sağlık merkezine gitmektedirler ve bu nedenle yaşadıkları yere ulaşımı en kolay olan aile sağlığı merkezini tercih etmektedirler. Devlet hastaneleri ve üniversite hastanelerinde gerek çok sıra olması gerek de takipte oldukları hekimin yoğunluğundan dolayı hastalar sağlık hizmetine erişmekte güçlük çekebilmektedirler. $\mathrm{Bu}$ konuda yapılan tüm çalışmalarda hastalar ulaşım faktörünün öneminden bahsetmiş, yeri geldiğinde saat ve gün fark etmeksizin aile hekimine telefon yolu ile dahi ulaşabilme isteklerinden bahsetmişlerdir [10, 12, 13].

DM sürekli ve düzenli bakım gerektiren bir hastalıktır. Sürekli bakımın gerçekleşebilmesi için hastaya da çok şey düşmektedir. Bu noktada hastaların işini kolaylaştıran durumlardan biri takipte olduğu hekimin hastasını çok iyi biliyor olması ve yönetim konusunda hastayı kişinin karakteristik özelliklerinden de faydalanarak tedaviye 
katabilme durumudur. Aile hekimliğinin çekirdek yeterlilikleri arasında olan kişi merkezli bakım özelliği bu noktada devreye girmektedir $[9,12,14]$.

Yine aile hekimliğinin çekirdek yeterliliklerinden olan kapsamlı yaklaşım hastaların aile hekimini tercih etme nedenleri arasında önemli bir yer almaktadır. DM kontrolleri sırasında diğer şikayetlerini de sunabilme lüksüne erişmek hastalar için büyük rahatlık olmaktadır. Hastaların da ifade ettikleri gibi DM takibi için gittikleri dahiliye, endokrin bölümlerinde hastaların bölüm dışı şikayetleri yanıtsız kalmaktadır. Bu anlamda da aile hekiminde takip olma hastalara bir artı sağlamaktadır. Bültzingslöwen ve ark. [12] da çalışmalarında bu konuya değinmiş ve özellikle yaşlı ve kronik bir hastalık sahibi bireylerin çoğuna, birden çok tanı konduğu ve hastaların bu durumu kendileri hakkında ayrıntılı bilgi sahibi olan ve kapsamlı yaklaşımda bulunabilen aile hekimlerinin çözebileceğine güvendiklerini belirtmiş̧lerdir. Bu konu ile ilgili yapılan başka çalışmalar da Bültzingslöwen'in çalışmasını destekler niteliktedir [11, 15].

Hastaların aile hekimi ve aile sağlığı merkezinden beklentilerini de sorguladığımız çalışmamızda yukarıda bahsettiğimiz kolay ulaşım, güven faktörlerinin dışında dikkat çeken hastaların doktorlarından samimi ve sıcak bir yaklaşım beklemeleridir. Hastaların aile ortamını hissetmek istedikleri aile sağlığı merkezlerinde hekimin ve diğer sağlık çalışanlarının hastayı karşıladığ 1 andan itibaren sıcak ve samimi bir tavır içinde olmaları beklenmektedir. Hastaların hekimden beklentilerinin sorgulandığı diğer çalışmalarda da bu konudan çok bahsedilmektedir [10, 16, 17].

Çalışmamızda çoğu hasta tarafından pek de önemsenmeyen hekimin cinsiyetinin öneminden bazı hastalar 1srarla bahsetmişlerdir. $\mathrm{Bu}$ noktada özellikle bayanların mahremiyeti koruma isteği, şikayetlerini daha kolay dile getirebilme rahatllğı ve iki cins içinde kıskançlık çalışmamızda hastaların hekimin cinsiyetini ciddiye almaları noktasında ön plana çıkmaktadır. Güldal ve ark.'nın [10] çalışmasında hastaların hekimden beklentileri konusunda hekimin cinsiyeti ve yaşı ön plana çıkmamıştır. Yine Samsun'da Tıp Fakültesinde yapılan çalışmada cinsiyetin hastaların beklentileri arasında olmadığı saptanmıştır [18].

Çalışmamızda ilgi çeken bir nokta ise hekimin uzmanlık durumunun özellikle tercih ediliyor olmasıdır. Ülkemizde aile hekimliği uzmanlığı henüz yeni yeni halk arasında yer etmektedir. $\mathrm{Bu}$ konuda hastaların bilinçlendiğini görmek çalışmamızın sevindirici yanlarından biridir.

Sonuç olarak; sağlik hizmetleri içinde çok önemli bir yere sahip olan birinci basamak sağlık sistemlerinde kronik hasta takibinin önemine dikkat çekilmek istenen ve hastaların görüşleri alınarak bu konuda geliştirilmesi gereken özelliklerin saptanması amaçlanan çalışmamızda, birinci basamak sisteminin çekirdek yeterliliklerinin, DM gibi kronik hastalıkların yönetiminde hastaların beklentileri doğrultusundaki gereken özellikleri karşıladığ 1 saptandı.

Çalışmamızın, birinci basamak sağlık sistemlerinin geliştirilmesi ve iyileştirilmesinde önemli görevleri olan aile hekimlerinde kronik hasta takibi konusunda farkındalığ 1 artıracağ1 görüşündeyiz.

Kantitatif çalışmaların kalitatif çalışmalar ile desteklenerek yapılacağı ileri araştırmalarla birinci basamakta hem hasta hekim iletişimini artırmak hem de kronik hastalık yönetiminde başarıyı artırmak mümkün olabilir. $\mathrm{Bu}$ tarz çalışmalara ihtiyaç olduğu görülmektedir. 


\section{Kaynaklar}

1. Dikici MF, Kartal M, Alptekin S,Çubukçu M, Ayanoğlu AS, Yarıs F. Aile hekimliğinde kavramlar, görev tanımı ve disiplininin tarihçesi. Turkiye Klinikleri J Med Sci 2007; 27: 412-8.

2. Sipkoff M. Health plans begin to address chronic care management.Manag Care 2003; 12: 24-31.

3. Akman M, Çifçili S. Aile hekimliği ve kronik hastalık bakım modeli. Türk Aile Hek Derg 2010; 14: 32-7.

4. Topallı R, Aladaş N, Filiz TM, Topsever P, Ciğerli Ö, Görpelioğlu S. Tip Fakültesi Aile Hekimliği polikliniklerinin sağlk hizmeti sunumundaki yeri: Değirmendere deneyimi. Türk Aile Hek Derg 2003; 7: 165-70.

5. Satman İ, Alagöl F, Ömer B. Türkiye Diyabet, Hipertansiyon, Obezite ve Endokrinolojik hastalıklar prevalans çalışması-II (TURDEP-II). www.turkendocrin. org/files/fileD_156.pdf (Erişim tarihi: 01.04.2014).

6. Lloyd, Bor H, R. Communication Skills For Medicine, London Churcill Livingstone Inc 1996.

7. Winefield HR, Chur-Hansen A. "Evaluating The Outcome Of Communication Skill Teaching For Entrylevel Medical Students: Does Knowlegde Of Emphaty İncrease?" Medical Education 2000; 34: 90-4.

8. Hancock B. An Introduction to Qualitative Research, Trent Focus for Research and Development in Primary Health Care 2002; 2-18.

9. The European Definition of General Practice/Family Medicine. Wonca Europe Edition 2011; 8-12.

10. Güldal D, Günvar T, Mevsim V, Kuruoğlu E, Yıldırım E. Aile hekimleri çekirdek yeterlilikleri hastaların beklentileri ile uyuşmakta mıdır? Türk Aile Hek. Derg 2012; 16: 107-12.

11. Infante FA, Proudfoot JG, Davies, GP, Bubner TK, Holton CH, Beilby JJ, Harris MF. How people with chronic illnesses view their care in general practice: a qualitative study. MJA 2004; 181: 70-3.

12. Bultzingslöwen T. Patients' views on interpersonal continuity in primary care: A sense of security based on four core foundations. Fam Pract 2006; 23: 210-9.

13. Schmittdiel JA, Shortell SM, Rundall TG, Bodenheimer T, Selby JV. Effect of Primary Health Care Orientation on Chronic Care Management. Ann Fam Med 2006; 4: 117-23.

14. Adler R, Vasiliadis A, Bickell N. The relationship between continuity and patient satisfaction: a systematic review. Fam Pract 2010; 27: 171-8.

15. Oldroyd J, Proudfoot J, Infante F. Providing healthcare for people with chronic illness: The views of Australian GPs. Med J Aust 2003; 179: 30-3.

16. Allen J, Gay B, Crebolder H, Heyrman J, Svab I, Ram P. The European definitions of the key features of the discipline of family practice: the role of the GP and core competencies. Br J Gen Pract 2002; 52: 526-7.

17. Gross R, Tabenkin H, Brammli-Greenberg S. Who needs a gatekeeper? Patients'views on the role of the family physician. Fam Pract 2000; 17: 222-9.

18. Sünter AT, Canbaz S., Tunçel EK, Çetinoğlu EÇ. Bir tıp fakültesi hastanesinde yatan hastaların memnuniyet düzeylerinin değerlendirilmesi. 9. Halk Sağlığ Günleri Bildiri Kitapçı̆̆ı, Ankara 2005; 474. 